\title{
The large-scale investigation of gene expression in Leymus chinensis stigmas provides a valuable resource for understanding the mechanisms of poaceae self-incompatibility
}

Qingyuan Zhou ${ }^{1 *}$, Junting Jia ${ }^{1}$, Xing Huang ${ }^{1}$, Xueqing Yan ${ }^{2}$, Liqin Cheng ${ }^{1}$, Shuangyan Chen ${ }^{1}$, Xiaoxia Li ${ }^{1}$, Xianjun Peng ${ }^{1}$ and Gongshe Liu' ${ }^{1}$

\begin{abstract}
Background: Many Poaceae species show a gametophytic self-incompatibility (GSI) system, which is controlled by at least two independent and multiallelic loci, $S$ and $Z$. Until currently, the gene products for $S$ and $Z$ were unknown. Grass SI plant stigmas discriminate between pollen grains that land on its surface and support compatible pollen tube growth and penetration into the stigma, whereas recognizing incompatible pollen and thus inhibiting pollination behaviors. Leymus chinensis (Trin.) Tzvel. (sheepgrass) is a Poaceae SI species. A comprehensive analysis of sheepgrass stigma transcriptome may provide valuable information for understanding the mechanism of pollen-stigma interactions and grass SI.

Results: The transcript abundance profiles of mature stigmas, mature ovaries and leaves were examined using high-throughput next generation sequencing technology. A comparative transcriptomic analysis of these tissues identified 1,025 specifically or preferentially expressed genes in sheepgrass stigmas. These genes contained a significant proportion of genes predicted to function in cell-cell communication and signal transduction. We identified 111 putative transcription factors (TFs) genes and the most abundant groups were MYB, C2H2, C3H, FAR1, MADS. Comparative analysis of the sheepgrass, rice and Arabidopsis stigma-specific or preferential datasets showed broad similarities and some differences in the proportion of genes in the Gene Ontology (GO) functional categories. Potential SI candidate genes identified in other grasses were also detected in the sheepgrass stigma-specific or preferential dataset. Quantitative real-time PCR experiments validated the expression pattern of stigma preferential genes including homologous grass SI candidate genes.

Conclusions: This study represents the first large-scale investigation of gene expression in the stigmas of an SI grass species. We uncovered many notable genes that are potentially involved in pollen-stigma interactions and SI mechanisms, including genes encoding receptor-like protein kinases (RLK), CBL (calcineurin B-like proteins) interacting protein kinases, calcium-dependent protein kinase, expansins, pectinesterase, peroxidases and various transcription factors. The availability of a pool of stigma-specific or preferential genes for L. chinensis offers an opportunity to elucidate the mechanisms of SI in Poaceae.
\end{abstract}

\footnotetext{
* Correspondence: qyzhou@ibcas.ac.cn

${ }^{1}$ Key Laboratory of Plant Resources, Institute of Botany, Chinese Academy of

Sciences, Nanxincun 20, Xiangshan, Beijing 100093, China

Full list of author information is available at the end of the article
} 


\section{Background}

Self-incompatibility (SI) is a widely distributed mechanism to prevent self-fertilization in flowering plants [1,2]. Classic genetic studies revealed two major classes of homomorphic SI, gametophytic (GSI) and sporophytic (SSI) systems [3]. Recent studies have focused on identifying molecules that mediate SI events. In Solanaceae, Rosaceae and Plantaginaceae GSI species, the stylar inhibition of incompatible pollen is mediated through an interaction between a stylar S-RNase (female determinant) and the pollen tube-borne F-box protein, SLF [4,5]. GSI in poppies (Papaveraceae) is mediated by a calcium-based signaling pathway that is most likely triggered by an interaction between a stigma-expressed S-glycoprotein ligand (a small extracellular signaling molecule) and its cognate plasma membrane receptor, which is a pollen-expressed $\mathrm{Ca}^{2+}$ channeled protein [6]. SSI in Brassicaceae is regulated by an S-haplotype-specific protein interaction between a stigma-specific S-receptor kinase (SRK, female determinant) and its cognate ligand S-locus cysteine-rich (SCR, male determinant) [7,8].

Poaceae exhibit a GSI system controlled by at least two independent and multiallelic loci $(S$ and $Z$ ) $[9,10]$. An incompatibility reaction occurs when both the $S$ and $Z$ alleles of the haploid pollen are matched in the pistil. The mechanisms of the grass GSI are poorly understood relative to the well-characterized single-locus GSI system mentioned above. Numerous efforts to identify the genes of the $S$ and $Z$ loci have been performed, but currently, the genes for $S$ or $Z$ on either the pollen or pistil side remain unknown $[10,11]$.

Li et al. [12] reported the putative pollen S-gene BM2 identified from Phalaris coerulescens, which is a grass SI species. This gene was originally observed to co-segregate with the $S$ genotype. Later studies indicated that $B M 2$ encodes a functional thioredoxin protein, which is possibly involved in post-translational protein modification and is located at ca. $1 \mathrm{cM}$ from the $S$-locus [9]. Hackauf and Wehling [13] identified a putative ubiquitin-specific protease (UBP) gene with a pistil-specific expression pattern and co-segregation with the $Z$-locus, thus suggesting the potential involvement of protein ubiquitination in the grass SI system. However, whether the UBP gene is a component of the $Z$-locus or a linked gene with suppression recombination around the $Z$ locus is unknown [14]. Kakeda [15] isolated two F-box genes in Hordeum bulbosum based on the partial clone HAS175, which is an anther-derived marker showing complete linkage to the $S$ locus. Yang et al. [11] constructed subtractive hybridization cDNA libraries to enrich the SI expressed genes in Lolium perenne.

There are certain physiological characteristics of grass SI that resemble features of the Papaver system and Brassica SSI including the dry stigma type and a rapid response to stigma-pollen interactions [14]. In these three SI systems, the stigmas critically discriminate between compatible and incompatible pollen grains and promote compatible pollen growth while preventing incompatible pollen adhesion, hydration, germination or invasion. To fulfill these unique functions, stigmas should express genes that encode the proteins required for appropriate development of and accomplishment in pollen-stigma interactions. It is likely that many of these genes are stigma-specific or preferential. To gain a better understanding of the molecular basis of stigma development and pollen-stigma interactions, it is important to generate a near-complete catalog of genes expressed specifically or preferentially in stigma cells.

Currently, genome-wide transcriptome analyses of wet, dry and semidry stigmas have been conducted on tobacco [16], Arabidopsis [17,18], rice [19], maize [20] and Senecio squalidus [21]. However, stigma transcriptome data sets are not available in SI species of the Poaceae, the fourth largest family of flowering plants, which includes all cereal crops and major cultivated forage crops [22]. To develop insight into the conserved and diverse aspects of stigma development and functions across multiple species, it is useful to expand the available transcriptomic resources for incompatible species to allow comparative analysis.

Leymus chinensis (Trin.) Tzvel. (sheepgrass), a member of the tribe Triticeae, is a key dominant species of typical grassland communities in the Eurasian steppe region with economic and ecological value. The species is one of most important forage crops for grazing animals in China and is important in environmental protection, including soil and water conservation [23]. L. chinensis is a GSI species with incompatibility responses occurring on the stigma surface before or immediately after pollen germination [24].

The aims of the present study were to search for genes expressed specifically or preferentially in the stigma of the incompatible grass plant at the entire genome level using high-throughput next generation sequencing technology to perform an RNA-seq analysis on the stigmas, leaves and ovaries of $L$. chinensis. Here, the gene expression profiling of various tissues identified 1,025 genes that were predicted to be specifically or preferentially expressed in the stigma. The stigma gene sets were significantly enriched in cellcell communication and signal transduction mechanisms, intracellular trafficking, secretion and vesicular transport. Our results also indicated that the sheepgrass stigmas shared common SI candidate genes, such as kinase genes, identified in Lolium. To our knowledge, this study is the first large-scale survey of gene expression in the stigmas of an SI grass species. The availability of a pool of stigmaspecific or preferential genes for L. chinensis offers an opportunity to elucidate the molecular mechanisms of pollen-stigma interactions and SI in Poaceae. 


\section{Results}

The identification of stigma-specific or preferential genes To identify the genes involved in stigma development and required for unique stigma functions, we performed an RNA-seq analysis on the stigmas, leaves and ovaries of Leymus chinensis. These three samples enabled us to distinguish stigma-specific transcripts from transcripts that contribute to common cellular activities and functions. Mature stigmas, which were unpollinated and reached the largest expansion, were collected from the pistils just before anther dehiscence to avoid contamination with pollen grains (Figure 1). The stigmas were excised by cutting the pistil just below the base of the plumose stigma, and the remainder of the pistil was used as an ovary sample. Approximately 1,500 stigmas, 1,500 ovaries and 20 leaves of 10-day old seedlings were collected for each RNA preparation. The mRNA from the three tissues was used to construct cDNA libraries, which were then sequenced on an Illumina HiSeq 2000 system. Paired-end 100-bp sequence reads were then generated. After quality control, $8,351,351,6,046,077$ and 5,654,202 high-quality reads were obtained from the stigmas, ovaries and leaves libraries, respectively.

In previous studies, we performed long-read transcriptome sequencing of several cDNA libraries from different tissues of sheepgrass, including flowers before and after pollination and leaves, using a Roche 454 GS FLX sequencer [23]. A total of 87,214 unigenes were obtained,

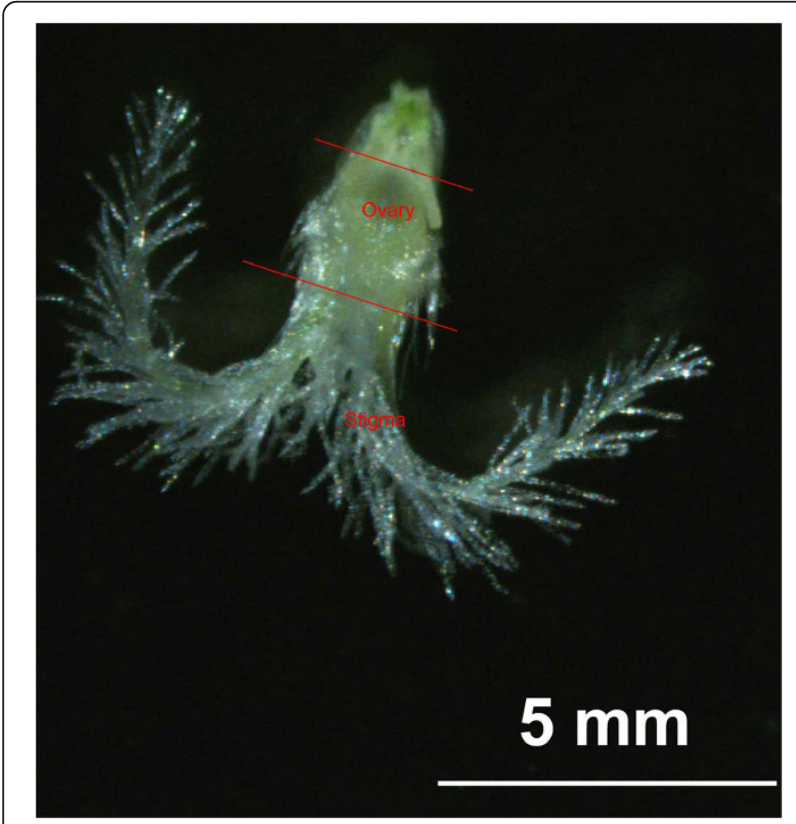

Figure 1 The mature pistil that was collected just before anther dehiscence. A long red line showing the position where a stigma was excised and a short red line showing the cutting position between ovary and rachis. including 32,416 contigs and 54,798 singletons. The mean contig size was $607 \mathrm{bp}$. To identify the genes that corresponded to the sequencing reads in each library of the present study, the purity-filtered high-quality reads were mapped against the reference transcriptome dataset, which was generated using Roche 454 pyrosequencing technology. Altogether, 26,325, 29,748 and 30,620 contigs were detected at the stigmas, ovaries and leaves, respectively (Additional file 1). The stigma contigs, ovary contigs and leaf contigs represent about $81.2 \%, 91.8 \%$ and $94.4 \%$ of the total contigs of the Roche 454 sequencing dataset, respectively. Of these unigenes, 25,501 were common to all three tissues (Figure 2). A substantial number of genes showed tissue-specific expression: 183 in the stigma, 683 in the ovary, and 1,432 in the leaves.

Using a fold change of $>1$, false discovery rate (FDR) of $<1$ e- 05 as a cutoff to identify differentially expressed genes, 842 contigs were up-regulated in the stigma compared to the ovary and leaf (Additional file 2 and Additional file 3). These contigs were considered to be preferentially expressed in the sheepgrass stigma. Thus, 1,025 (183 plus 842) contigs were specifically or preferentially expressed in the stigma (hereafter designated the stigma dataset) (Additional file 4).

\section{Confirmation of stigma-specific or preferential genes by real time PCR analysis}

To validate the expression of the genes detected by the RNA-seq analysis, 18 genes with different expression patterns in the stigmas and leaves were selected for realtime PCR analysis (the primer sequences are available in Additional file 5). Scatterplots were generated by comparing the $\log 2$ fold change determined by the transcriptome

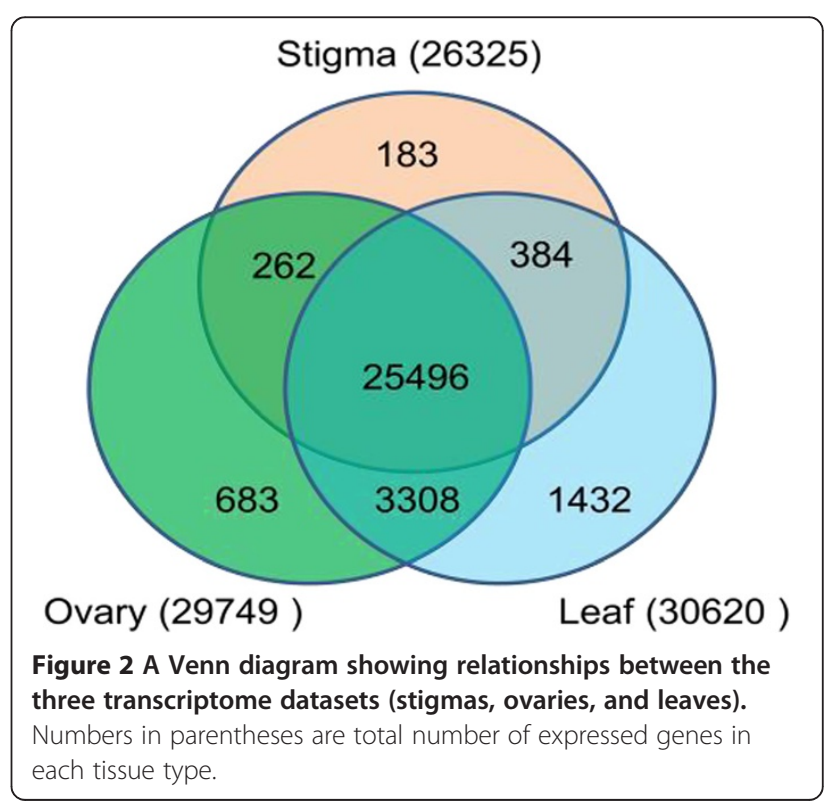


analysis and real time PCR. The correlation between these two analyses was then evaluated. The results showed that the expression patterns of these genes examined by real time PCR were well correlated with those by RNA-seq $\left(R^{2}=0.811\right)$, thus supporting the reliability of our RNAseq data (Figure 3).

\section{KOG annotation of the stigma-specific or preferential genes}

From the 1,025 contigs specifically or preferentially expressed in the stigma, 648 contigs had putative functions and 377 contigs were assigned as hypothetical proteins (Additional file 4) based on BLASTX similarity searches against the Swiss-Prot and NCBI non-redundant protein sequences $(\mathrm{nr})$ databases. The 648 contigs were further annotated and classified based on EuKaryotic Orthologous Groups (KOG) categories. Altogether, 522 contigs were assigned KOG functional annotations (Additional file 4) and grouped into 23 functional categories (Figure 4). Among the KOG categories, "Signal transduction mechanisms" (14.8\%) was the most abundant (Additional file 6).

\section{Gene ontology (GO) annotation}

Gene ontology (GO) assignment programs were utilized for the functional categorization of annotated unigenes of the sheepgrass stigma dataset. In many cases, multiple terms were assigned to the shared contig. A total of 420 contigs were categorized into 40 main functional groups belonging to 3 categories (biological processes, molecular functions, and cellular components). The GO terms of their subcategories are presented in Figure 5.

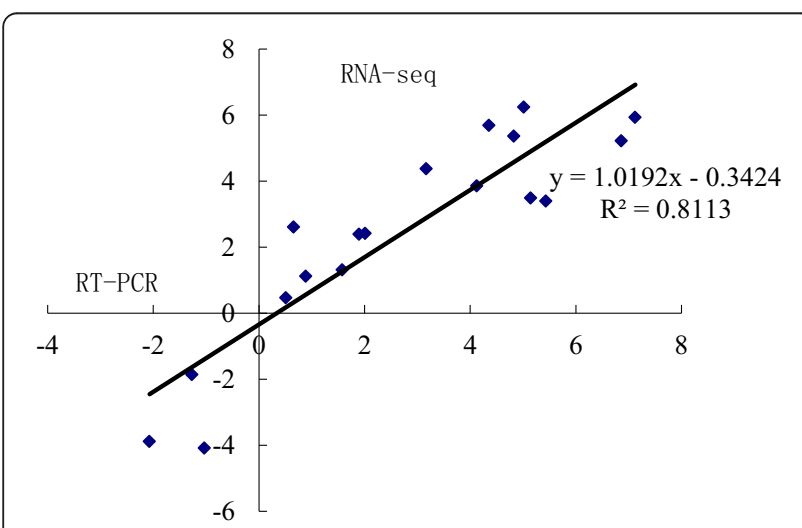

Figure 3 Validation of RNA-seq results by quantitative real time RT-PCR. Correlation plots indicating the relationship between GPCR results (fold change; $Y$-axis) of 18 selected genes expressed in the stigmas and leaves and the corresponding data from RNA-seq analysis (X-axis)
A comparison of the GO classification of stigma-specific or preferential genes in sheepgrass, rice and arabidopsis The stigma-specific or preferential expressed gene datasets of rice [19] and Arabidopsis [17], two compatible species, are available to provide the opportunity to compare the diversity and conservation of stigma-specific or preferential genes in species of mono- and dicotyledons. A total of 462 unigenes of rice stigmas and 115 of Arabidopsis stigmas were categorized into functional groups using the GO assignments. The WEGO online tool [25] was used to classify the GO functions for all genes of the sheepgrass, rice and Arabidopsis stigma-specific or preferential datasets to understand the distribution of gene functions at the macro level. The comparative analysis showed that these three stigma transcriptomes shared broad similarities in the proportion of genes in the three main categories and many subcategories (Figure 5). However, differences were also detected among the three species. The high proportions of genes involved in the GO terms "protein tag", "translation regulators", "cell killing", and "rhythmic process" were only represented in the sheepgrass stigma dataset. The genes of the GO term "symplast" were only observed in Arabidopsis. These results suggest that despite the differences in the relationship and gross stigma morphology among these three diverse species, certain conserved mechanisms of structural development and the pollen-stigma interaction process appear to be common. Conserved stigma-specific genes may be evidence of the convergent evolution of classes of genes to acquire stigma-specific functions in diverse angiosperm species. Unique genes in the sheepgrass stigma dataset may imply intrinsic differences in stigma development and the pollination process between compatible and incompatible species.

\section{GO enrichment analysis}

A singular enrichment analysis (SEA) [26] was performed to identify the significantly enriched GO terms in genes specifically or preferentially expressed in sheepgrass stigma. The results showed that 19 GO terms were overrepresented in the stigma based on a P-value $<0.001$ and the FDR $\leq 0.05$ cutoffs, which were 13, 3 and 3 for the cellular components, biological processes, molecular functions categories, respectively. The detailed results of the Go enrichment analysis are presented in Table 1.

\section{Kyoto encyclopedia of genes and genomes (KEGG) pathway mapping}

The genes of the sheepgrass stigma dataset were annotated based on the Kyoto Encyclopedia of Genes and Genomes (KEGG) databases [27]. The results showed that KEGG numbers could be assigned to 128 contigs (Additional file 4). These unigenes were further annotated to BRITE functional hierarchies. The BRITE functional 


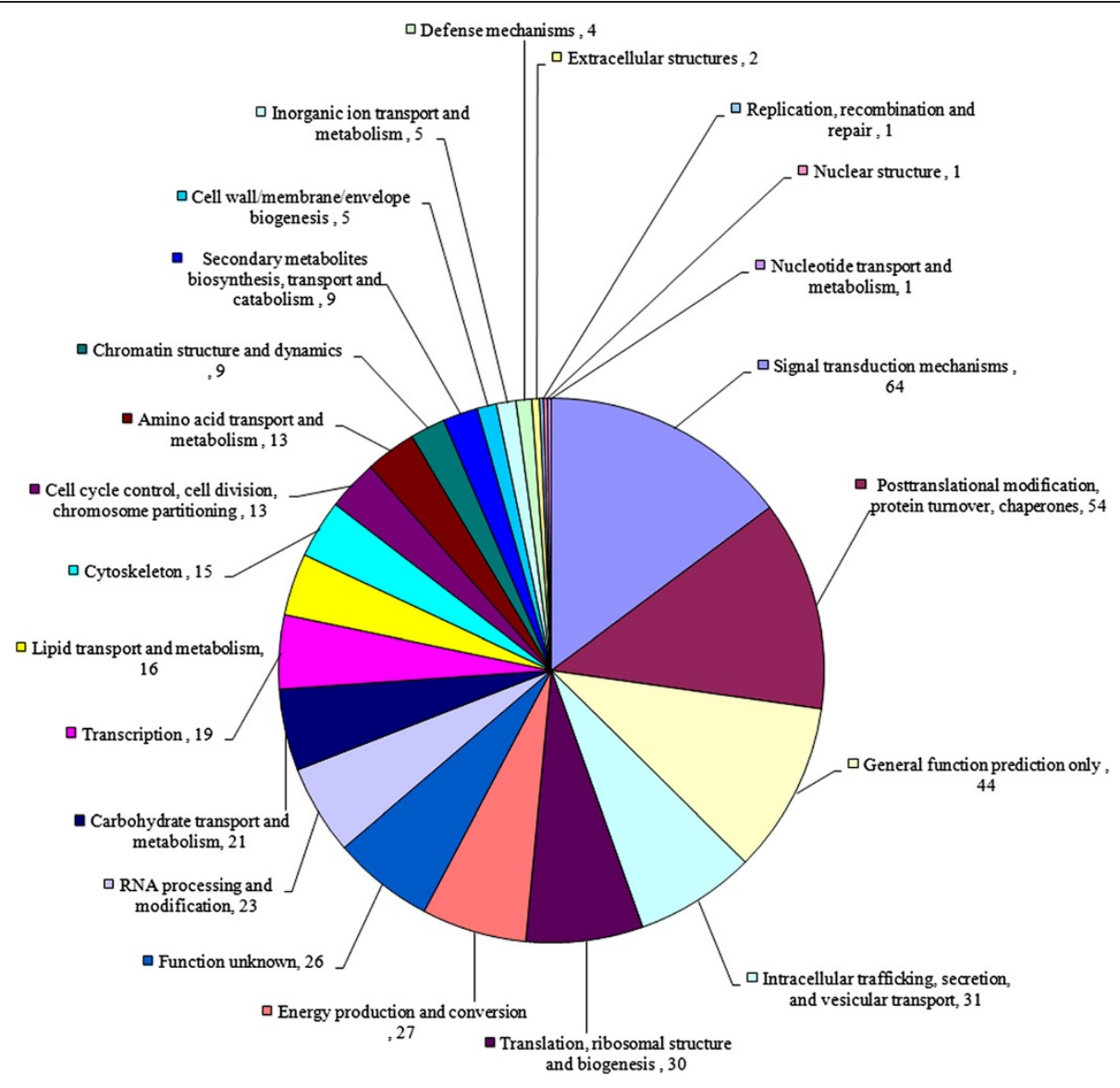

Figure 4 KOG function classification. The unigenes were aligned to the KOG database to predict and categorize possible functions. A total of 522 unigenes were assigned to 23 categories.

mapping categorized the unigenes into diverse KEGG pathways (Figure 6).

\section{Putative transcription factors in the sheepgrass stigma dataset}

Understanding transcription factors (TFs) patterns of expression is of particular interest because the expression and activity of these regulatory proteins is crucial for controlling the expression of numerous genes, and thus, their ability to regulate biological pathways and developmental processes. We searched the TFs in the sheepgrass stigma dataset using a BLASTX search against the PlnTFDB (Plant Transcription Factor Database) (version 3.0) (E-value $\leq 1 \mathrm{e}-10)$. We identified 111 putative TF unigenes from the sheepgrass stigma dataset. These unigenes were clustered into $26 \mathrm{TF}$ families. The top 19 TF families in the sheepgrass stigma dataset are shown in Figure 7.

\section{Sheepgrass stigmas share certain potential SI candidate genes identified in other grasses}

Yang et al. [11] identified 10 expressed SI candidate genes for the $S$ and $Z$ loci in $L$. perenne from the SI cDNA libraries. We compared gene sequences from Lolium with the sheepgrass unigene set to reveal the conservation of stigma preferential genes among different SI grass stigmas. The nucleotide sequences of 10 Lolium SI candidate genes (Can135, accession number AM991118; Can130, AM99 1119; Can10, AM991120; Can136, AM991121; Can18, AM991122; Can3, AM991123; Can94, AM991124; Can4, AM991125; Can139, AM991126; and Can151, AM991 127) were extracted from GenBank and blasted against the sheepgrass dataset containing 87,214 unigenes. Significantly similar sequences (using an $\mathrm{E}$ value $\leq 1 \mathrm{e}-05$ ) were identified for all 10 Lolium SI candidate genes. Nine of the ten best hits were included in the sheepgrass stigma dataset and four (contig23066, contig15874, contig23698, and contig24204) were included in the 1,025 specific or preferential unigenes dataset (Table 2). An RT-PCR analysis confirmed the stigma-preferential expression for these four contigs (Figure 8). The Lolium SI candidate genes that had the best hits in the sheepgrass stigma gene dataset included all three predicted kinase genes and a kinase-partner gene of the 10 SI candidate genes, i.e., Can3 (predicted as a CBL-interacting serine/ 


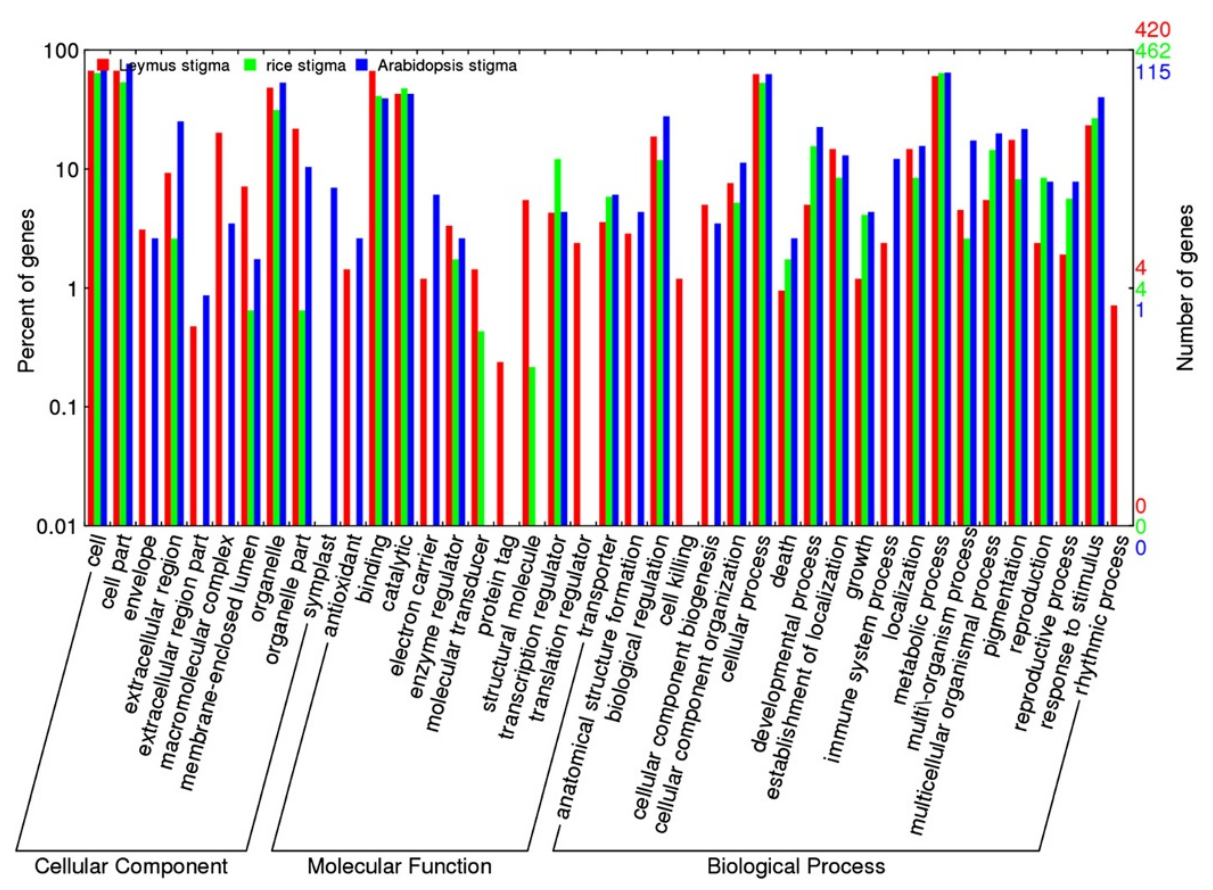

Figure $5 \mathrm{GO}$ assignment of all identified genes expressed specifically or preferentially in the stigmas of sheepgrass, rice and Arabidopsis. The genes were mapped to three main categories: biological processes, cellular components and molecular functions. The right hand $y$-axis indicates the number of annotated genes.

threonine-protein kinase 15), Can94 (predicted as a calcium-dependent protein kinase), Can4 (predicted as a serine/threonine-protein kinase NAK), and Can136 (predicted as a pollen-specific kinase partner protein). Two (Can3 and Can4) of the three predicted kinase genes and the kinase-partner gene showed significant similarities to the unigenes of the specific and preferential sheepgrass stigma gene set, thus indicating a potential role for kinase activity and conserved functional mechanisms in the grass SI response.

It was proposed that $B m 2$ identified from P. coerulescens was involved in the SI response through the post-translational modification of other proteins by thioredoxin proteins [9]. To detect whether the $B M 2$ gene was expressed in sheepgrass, we blasted the gene sequence of BM2 (GenBank: AF159388.1) against the sheepgrass unigene set. The result indicated that $B m 2$ matched three unigenes (contig12829, contig12830, and contig1 2832 ) with significantly similar sequences (identity $>80 \%$, E-value $\leq 1 \mathrm{e}-10$ ). The RT-PCR experiments validated that contig12830 was expressed in mature sheepgrass stigmas, thus suggesting that the $B M 2$ gene plays an important role in the SI process.

\section{Discussion}

The present studies have identified 1,025 genes predicted to be specifically or preferentially expressed in the stigmas of sheepgrass using high-throughput next generation sequencing technology to perform an RNA-seq analysis. This is a minimium estimate because of stringent filtering process we used in analyzing HiSeq 2000 sequencing data, incomplete detection of the expressed genes based on Roche 454 sequencing, decrease in the number of identifed genes mapped against the Roche 454 reference dataset compared to those of actually expressed genes in each tissue. It is likely that at least some of the specific or preferential sheepgrass stigma genes identified in this study function in development of the stigma papillary cells and pollen-stigma interactions. Our analysis of the stigma transcriptome demonstrates the unique features of the stigma transcriptional profile. The functional specialization of the stigma for extracellular interactions is reflected by an increased number of stigma-specific or preferential expressed genes involved in signal transduction, such as kinases, receptor-like kinases and calcineurin B-like proteins $(\mathrm{CBL})$, the manufacturing of enzymes that most likely facilitate the entry of the pollen tube into the stigma, transcription factors that are possibly implicated in the pollination process, and defense-related genes that function in the defense against pathogens or potentially in response to pollination. It is hypothesized that some of these genes are potentially involved in the pollination response and SI mechanisms. 
Table 1 The overrepresented functional GO terms of the sheepgrass stigma-specific or preferential genes

\begin{tabular}{|c|c|c|c|c|c|c|c|}
\hline GO term & Ontology & Description & $\begin{array}{l}\text { No. of the elements } \\
\text { in the whole } \\
\text { transcriptome }\end{array}$ & $\begin{array}{l}\text { No. of elements } \\
\text { differentially } \\
\text { expressed }\end{array}$ & $\begin{array}{l}\text { No. of elements } \\
\text { expected to be } \\
\text { differentially }\end{array}$ & $p$-value & FDR \\
\hline GO:0009065 & $P$ & $\begin{array}{l}\text { Glutamine family amino } \\
\text { acid catabolic process }\end{array}$ & 39 & 7 & 0.651 & $9.80 \mathrm{E}-06$ & 0.0078 \\
\hline GO:0009651 & $P$ & Response to salt stress & 273 & 17 & 4.578 & 7.60E-06 & 0.0078 \\
\hline GO:0006970 & $P$ & Response to osmotic stress & 336 & 18 & 5.641 & $2.80 \mathrm{E}-05$ & 0.015 \\
\hline GO:0005509 & $\mathrm{F}$ & Calcium ion binding & 457 & 25 & 7.669 & $5.60 \mathrm{E}-07$ & 0.00029 \\
\hline GO:0050897 & $\mathrm{F}$ & Cobalt ion binding & 40 & 7 & 0.6678 & 1.10E-05 & 0.0029 \\
\hline GO:0004857 & $\mathrm{F}$ & Enzyme inhibitor activity & 150 & 11 & 2.5158 & 7.90E-05 & 0.014 \\
\hline GO:0030529 & C & Ribonucleoprotein complex & 1072 & 42 & 17.997 & $6.30 \mathrm{E}-07$ & 0.00029 \\
\hline GO:0005624 & C & Membrane fraction & 94 & 9 & 1.5779 & 5.30E-05 & 0.0043 \\
\hline GO:0005753 & $C$ & $\begin{array}{l}\text { Mitochondrial proton-transporting } \\
\text { ATP synthase complex }\end{array}$ & 18 & 5 & 0.2982 & $3.20 \mathrm{E}-05$ & 0.0043 \\
\hline GO:0005792 & C & Microsome & 55 & 7 & 0.9231 & $7.20 \mathrm{E}-05$ & 0.0043 \\
\hline GO:0042598 & C & Vesicular fraction & 55 & 7 & 0.9231 & 7.20E-05 & 0.0043 \\
\hline GO:0005768 & C & Endosome & 149 & 11 & 2.5015 & $7.50 \mathrm{E}-05$ & 0.0043 \\
\hline GO:0005626 & C & Insoluble fraction & 95 & 9 & 1.5947 & $5.80 \mathrm{E}-05$ & 0.0043 \\
\hline GO:0032991 & C & Macromolecular complex & 3407 & 87 & 57.1998 & $4.80 \mathrm{E}-05$ & 0.0043 \\
\hline GO:0000267 & C & Cell fraction & 122 & 9 & 2.048 & 0.00034 & 0.017 \\
\hline GO:0070013 & C & intracellular organelle lumen & 926 & 30 & 15.5467 & 0.00064 & 0.027 \\
\hline GO:0043233 & C & Organelle lumen & 926 & 30 & 15.5467 & 0.00064 & 0.027 \\
\hline GO:0031974 & C & Membrane-enclosed lumen & 941 & 30 & 15.7983 & 0.00082 & 0.032 \\
\hline GO:0000502 & C & Proteasome complex & 141 & 9 & 2.3671 & 0.0009 & 0.032 \\
\hline
\end{tabular}

\section{Cell-cell communication and signal transduction}

Genes predicted to function in cell-cell communication and signal transduction are particularly notable in the context of pollen-stigma interactions and SI. The sheepgrass stigma dataset contained a significant proportion of genes consistent with the primary recognition role of the stigma in discriminating genotypes of pollen grains. The most noteworthy are genes encoding various putative protein kinases, including probable receptor-like protein kinases (RLK), mitogen-activated protein kinases (MAPKs), serine/threonine-protein kinase, CBL-interacting protein kinases, and calcium-dependent protein kinase.

A stigma-specific receptor kinase, SRK, which was most extensively studied in Brassicaceae, interacts with the ligand (SCR) held on the pollen coat and initiates a signal transduction cascade that inhibits the growth of self-pollen and the pollen tube [28]. In the Papaver GSI mechanism, the female S-determinant (PrsS) is a small stigma-secreted signal peptideand acts as a signaling ligand. The male S-determinant (PrpS) has a small predicted extracellular domain that has been shown to be involved in both binding to PrsS and mediating SI [29]. A model for the operation of SI in Papaver has proposed that PrsS acts as a signaling ligand that interacts with PrpS. The sheepgrass stigma dataset contained 3 contigs, i.e., contig24113, contig28482, and contig24154, which are predicted to encode probable receptor-like protein kinase At2g42960, a probable LRR receptor-like serine/threonine-protein kinase At1g63430, and somatic embryogenesis receptor kinase 1, respectively. A homologous gene encoding receptor-like protein kinase At1g63430 was also identified in the Senecio squalidus SSI stigma preferential gene dataset. The contig24113, contig28482 and contig24154-encoded proteins may have a potentially important role in cell-cell communication and signal transduction in the context of pollenstigma interactions and are therefore notable candidates for further studies of sheepgrass stigma SI mechanisms.

MAPKs are key contributors in signal transduction mechanisms and regulate important cellular processes, including cell proliferation, survival, and death in eukaryotes [30]. In addition, MAPKs are known to be involved in the activation of plant defense responses and result in programmed cell death $(\mathrm{PCD})$ and pathogen resistance [30,31]. A MAPK, p56, is responsible for mediating SI induced PCD in Papaver [32,33]. p56 is involved in the loss of pollen viability, stimulation of caspase 3 like (DEVDase) activity and later DNA fragmentation in incompatible pollen [33]. We also identified two contigs, 


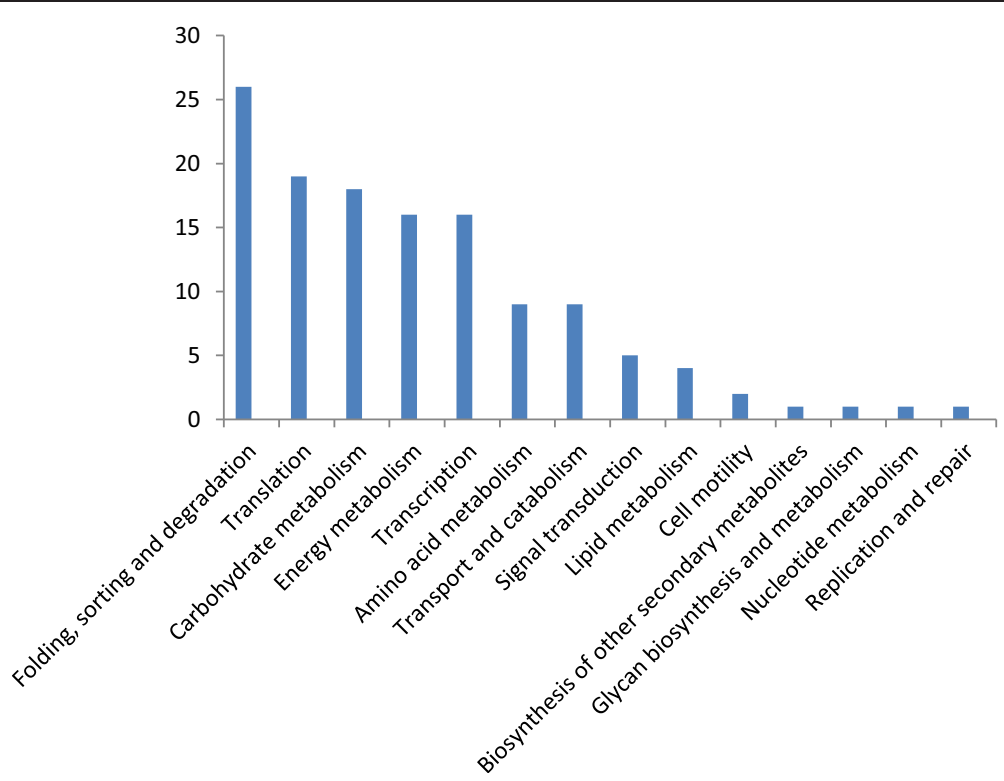

Figure 6 Histogram presentation of the KEGG pathway categories. The Y-axis indicates the number of unigenes assigned to a specific pathway. The $X$-axis indicates the KEGG pathway.

contig13945 and contig34021, in the sheepgrass stigma dataset that are predicted to encode for mitogenactivated protein kinase 10 and mitogen-activated protein kinase 1, respectively. The presence of MAPKs in the sheepgrass stigma gene dataset implies that they are likely involved in the early steps of pollination and SI responses.

Temporal and spatial changes in cytosolic $\mathrm{Ca}^{2+}$ concentrations generate specific $\mathrm{Ca}^{2+}$ signals, which are decoded by $\mathrm{Ca}^{2+}$ sensors $[34,35]$. As a class of calcium-sensing

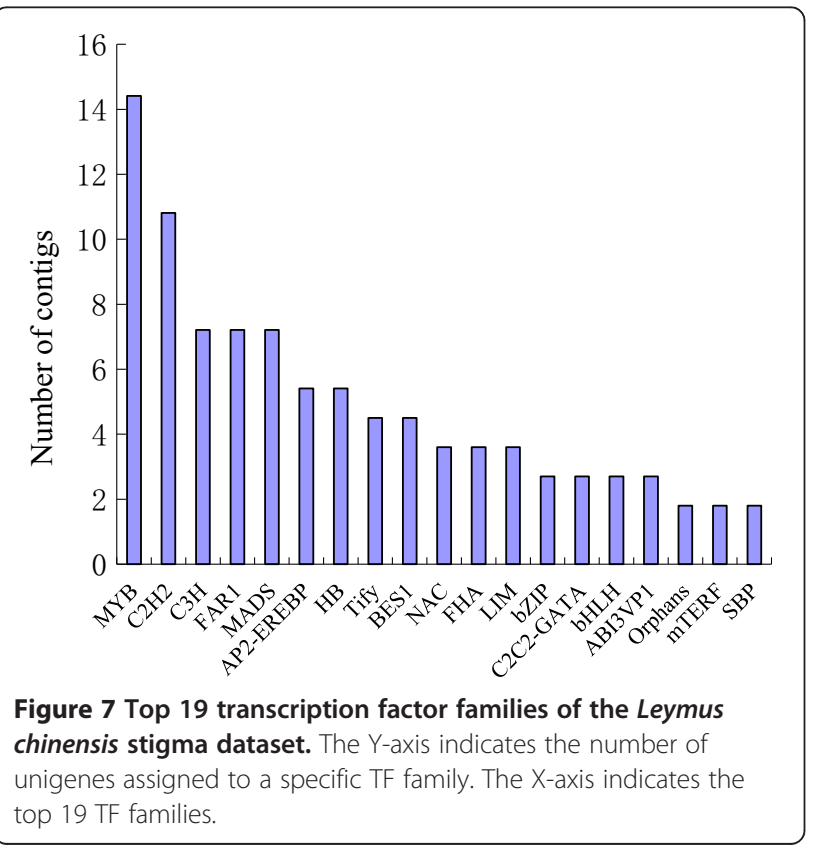

proteins, calcineurin B-like proteins (CBLs) specifically target a group of sucrose non-fermenting-related serine/ threonine kinases (SnRK3), named CBL-interacting protein kinases (CIPK), to mediate the sensed calcium signal [36-40]. The CBL-CIPK system is involved in a wide range of signaling pathways, including abiotic stress responses to drought and salt, innate immunity, plant hormone responses and $\mathrm{K}^{+}$channel regulation $[41,42]$. No CBLs or CIPKs have been implicated as signaling components in plant SI mechanisms. It is particularly notable that four contigs encoding CBL were observed in the analysis of the sheepgrass stigma dataset. These novel genes were not previously identified as pistil-specific or preferential in other species. It was previously mentioned that the Can3 (AM991123) gene, which putatively interacts with CBL, was identified in L. perenne stigma [11]. These results provide new insights into the function of CBL during pollen-pistil interactions in plants and suggest that CBLs are potentially involved in SI mechanisms.

In addition, the sheepgrass stigma dataset also contained many notable unigenes that encode calcium-related proteins, such as calmodulin-like proteins, probable calciumbinding proteins (CML49, CML13, CML18, CML16, CML 22, CML21), and calcium-dependent protein kinases. The role of cytosolic free $\mathrm{Ca}^{2+}$ in the regulation of pollen tube growth has been well characterized [43,44]. It has been shown that calcium signaling is involved in the selfincompatibility response of Papaver and Brassica [45,46]. In analogy to Papaver and Brassica SI, there is some evidence for the involvement of $\mathrm{Ca}^{2+}$-mediated signaling in grass SI. The application of $\mathrm{Ca}^{2+}$ antagonists to isolated stigmas resulted in the inhibition or delay of 
Table 2 The unigenes of Leymus chinensis transcriptome dataset that best hit SI candidate genes in Lolium perenne

\begin{tabular}{llrr}
\hline Can - homology to Rice- annotation & The best hit to the Leymus chinensis unigene dataset & Identity (\%) & P-value \\
\hline Beta-expansin 2 precursor & contig34768 (not included in stigma) & 89.81 & $5.00 \mathrm{E}-46$ \\
Pathogenesis-related protein PRB1-3 precursor & 4-GJVU7SP04IOQ46 (in stigma) & 93.52 & $3.00 \mathrm{E}-38$ \\
Expressed protein & contig26721 (in stigma) & 91.98 & $2.00 \mathrm{E}-134$ \\
Pollen-specific kinase partner protein & contig23066 (included in 1025 unigene) & 91.52 & 90.45 \\
ELMO domain-containing protein 2 & contig15874 (included in 1025 unigene) & 91.22 & $5.00 \mathrm{E}-125$ \\
CBL-interacting serine/threonine-protein kinase 15 & contig23698 (included in 1025 unigene) & 92.53 \\
Calcium-dependent protein kinase & contig24124 (in stigma) & 90.13 \\
Serine/threonine-protein kinase NAK & contig24204 (included in 1025 unigene) & 95 \\
gtk16 protein & contig15929 (in stigma) & $3.00 \mathrm{E}-177$ \\
myb-like DNA-binding domain, SHAQKYF class & familyprotein contig 05419 (in stigma) & 92.31 \\
\hline
\end{tabular}

the SI response on self-pollination in $S$. cereale and L. perenne $[10,47]$. It is tempting to hypothesize that stigma $\mathrm{S}$ and $\mathrm{Z}$ determinants act as signal molecules in grass by interacting with the "self" pollen $\mathrm{S}$ and $\mathrm{Z}$ partners at the tube plasma membrane, thus inducing a $\mathrm{Ca}^{2+}$-mediated signal cascade that results in pollen tube inhibition. However, whether a $\mathrm{Ca}^{2+}$-mediated signaling cascade is involved in grass SI is unknown.

Many recent studies have also implicated $\mathrm{ROS} / \mathrm{H}_{2} \mathrm{O}_{2}$ as signaling molecules involved in plant reproductive processes such as pollen tube growth [48-50] and pollenstigma interactions $[51,52]$. Because peroxidases can generate and consume $\mathrm{H}_{2} \mathrm{O}_{2}$ [53], they should be considered as potentially important components of signal transduction pathways. Senecio squalidus stigmas accumulate high amounts of ROS, particularly $\mathrm{H}_{2} \mathrm{O}_{2}$, in their epidermal cells (papillae). The first plant peroxidase gene, SSP (stigma-

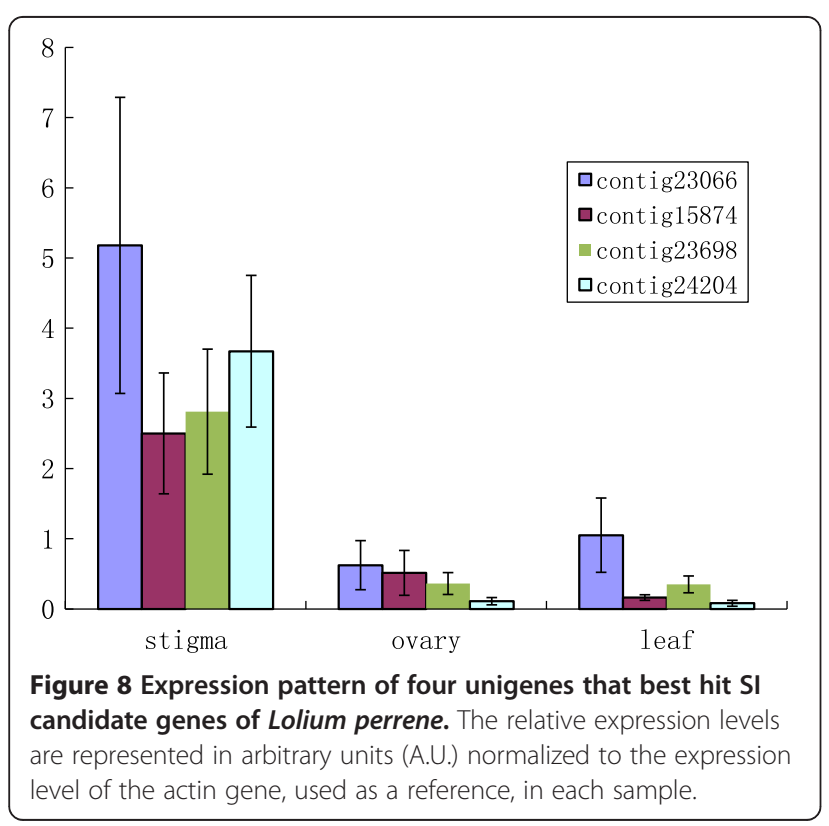

specific peroxidase), expressed specifically in stigma papillae was identified in S. squalidus [54]. In the sheepgrass stigma dataset, we detected two contigs that encode peroxidase. The potential signaling role of these interesting genes deserves further investigation.

\section{Enzymes most likely facilitating entry of the pollen tube into the stigma}

In flowering plants with dry stigmas, the stigmatic surface is covered by a continuous layer of cuticle, which is a significant barrier to pollen tube entry [55]. For successful pollination and subsequent fertilization, this barrier must be breached by cutinases from the pollen grain surface and stigma pellicle [56].

Cutinase is an esterase that degrades cutin [57-59]. Active cutinases have been detected in the pollen of Brassica [60] and Tropaeolum [61], in which they predominantly localize to the intine region of the pollen wall. Knox et al. [62] has suggested that esterases from the pollen and stigmatic pellicle combine to form an "active cutinase complex" which degrades the cuticle in the region of penetration. Although cutinases have been implicated in the process of pollen tube penetration in many species with dry stigmas, none have been fully characterized at the molecular level [63]. The identification of the genes that encode plant cutinases is important for elucidating the digestion mechanism of the stigmatic cuticle during pollen-stigma interactions. The sheepgrass stigma dataset contains three contigs that were predicted to encode GDSL esterase, two contigs for probable pectin esterase, and four contigs for pectin esterase inhibitor. These unigenes are very interesting candidates for further studies on enzymatic degradation of the stigmatic cuticle during pollination.

When the cuticle has been breached, pollen tubes invade the stigmatic papillary cell wall by growing between its outer and inner layers. The pollen tube then continues to grow through the intercellular spaces (extracellular matrix, ECM) of the transmitting tissue towards 
the ovary $[64,65]$. Much evidence has indicated that pollen- and stigma-derived enzymes and proteins most likely facilitate the entry of the pollen tube into the stigma by loosening the papillary cell wall and the ECM and/or modifying the growing pollen tube wall. These enzymes and proteins included expansins [66], pectin esterases [67], polygalacturonases [68], glucanases [69], xylanases [70], pectate lyases, pectin methylesterases [67], and peroxidases [71]. Lipid transfer proteins (LTP), one of the most abundant proteins present in the stigma of several species, have cell wall-loosening activity that is similar to expansion, despite its assumed role in lipid metabolism.

The sheepgrass stigma dataset contained many unigenes for putative cell wall-localized proteins that might function in regulating the expansion or loosening of the stigmatic papillary cell wall and ECM, thus regulating the entry of the pollen tube into the stigma. Among these proteins are two expansins, five pectinesterase, a pectin esterase inhibitor, two peroxidases, five polygalacturonases, three pectate lyases, and seven lipid transfer proteins. Because their better studied relatives exhibit cell wallloosening activity and have been implicated in ECM remodeling and the disassembly of ECM structural components, some of these proteins (e.g., expansins and hydrolase) may facilitate the penetration of the pollen tube into the stigma by modifying the papillary cell wall and ECM.

Expansins are cell wall-loosening proteins that regulate cell wall expansion and cell enlargement in a $\mathrm{pH}$ dependent manner [72]. The expansin superfamily (EXP) comprises four distinct families: expansin A (EXPA), expan$\sin \mathrm{B}(\mathrm{EXPB})$, expansin-like A (EXLA) and expansin-like B (EXLB) [73]. Experimental evidence has indicated that EXPA and EXPB proteins function in the loosening and extension of cell walls, whereas the exact functions of EXLA and EXLB remain unknown $[74,75]$. The sheepgrass stigma dataset contained $\mathrm{A}$ and $\mathrm{B}$ expansins. The latter have been suggested to act as cell wall-loosening agents to facilitate pollen adhesion and pistil penetration [76]. Yang et al. [11] also identified a prominent SI candidate, Can135, representing a putative EXPB protein in L. perenne stigmas. Because the assumed functions of expansins have been implicated in the process of pollen tube penetration, it is possible that the expansins expressed preferentially in sheepgrass stigmas might be related to pollen-stigma interactions and SI.

\section{Transcription factors possibly implicated in the pollination process}

The processes underlying pollen recognition and pollen tube growth require the concerted action of genes that are regulated by transcription factors [77]. A total of 111 unigenes encoding the transcription factors of 26 families were identified in mature sheepgrass stigmas. Most TFs (58\%) belonged to seven families: MYB, C2H2, C3H,
FAR1, MADS, AP2-EREBP, and HB. Among these families, the MYB genes form the largest category. Most plant MYB genes encode proteins of the R2R3-MYB class [78]. Numerous R2R3-MYB proteins are involved in the control of plant-specific processes including: primary and secondary metabolism, cell fate and identity, developmental processes, and responses to biotic and abiotic stresses $[79,80]$. For example, several R2R3-MYB proteins encoded by AtMYB0/GL1, AtMYB23 and AtMYB66/WER are involved in the determination of epidermal cell type. AtMYB0 and AtMYB23 control trichome initiation in shoots, whereas AtMYB66 controls root hair patterning [81]. Two closely related R2R3-MYBs, AtMYB88 and AtM YB124/FLP regulate stomatal differentiation and patterning. AtMYB98 regulates synergid cell differentiation during female gametophyte development, pollen tube guidance and the formation of the filiform apparatus [82]. Can151, which is an important SI candidate gene that represents a putative Myb-like protein, was identified in L. perenne stigmas [11]. MYB transcription factors were also detected in the stigmas of many other species, such as Arabidopsis $[17,18]$, rice [19], tobacco [16], maize [20], and crocus [83]. Similar to our studies, the transcriptome analysis of mature maize stigmas also indicated that the MYB genes represented the largest category of transcription factors. The preferential expression of MYB family genes in the mature or pollinated stigma of many species implicates its possible role in the pollination process and pollen-stigma interactions. Recently, Gómez-Gómez et al. [84] isolated CsMYB1, which is a transcription factor belonging to the R2R3 family gene, from Crocus sativus. CsMYB1 is highly expressed in stigma tissues and poorly expressed in tepals, whereas no transcript was detected in either anthers or leaves. CsMYB1's expression is developmentally regulated with no transcript detected in early stage stigmas but high levels occurring in later stages. It was assumed that CsMYB1 is possibly involved in the control of stigma morphological development. Although MYB genes have been identified and isolated in the stigma of many species, the precise functions of these ubiquitous stigma TFs in the pollination process are uncharacterized.

\section{Defense-related genes}

The stigmas of flowering plants are stubbornly resistant to pathogen invasion. Both wet and dry stigmas possess an effective pathogen defense system [1] and express a wide range of pathogenesis-related genes that presumably contribute to this stigmatic defense system $[17,18,85]$. These defense-related genes might function not only in defense against pathogens, but also in response to pollination. The mechanisms originally evolved in defense against pathogens may have been recruited to identify and reject self-pollen in an SI response [1]. The evidence indicated many striking similarities in the process of epidermal cell penetration by 
fungal spores and the pollen tube, including parallels in cell wall modification, the presence of phenolic derivatives, the accumulation of high levels of extracellular calcium, and the synthesis of $\beta 1-3$ glucan callose $[1,19]$.

Our transcriptome analyses have identified several stigma-specific or preferential genes that encode proteins potentially involved in defense responses, such as dihydroflavonol-4-reductase (DFR) and Bax inhibitor 1 (BI-1). DFR are key regulatory enzymes of flavonoid biosynthesis [86]. Flavonoids are ubiquitous plant secondary metabolites and are accumulated in different organs and tissues of plants [87]. Flavonoids are mainly involved in protecting plants against predation and pathogens (bacteria and fungi) [88]. High amounts of stigmatic flavonoids may be toxic to potential pathogens but are not toxic to pollen. It can be speculated that an unknown signaling mechanism identifies a pollen grain as a pollen grain and not a fungal spore or bacteria.

Plant cells can respond to various stimuli, including fungal toxins and biotic and abiotic stresses, by initiating programmed cell death. Bax inhibitor 1 proteins act as negative regulators of stress-related programmed cell death in plants and animals [89]. The stable overexpression of this cell death inhibitor in barley reduces susceptibility to the necrotrophic fungus Fusarium graminearum [90]. The transient or stable overexpression of BI-1 strongly supports the penetration of Blumeria graminis $\mathrm{f}$. sp. hordei into barley epidermal cells $[90,91]$. Here, we present the first report that genes encoding $\mathrm{BI}-1$ proteins were expressed in the stigma of flowering plants. However, further analysis is necessary to better understand the involvement of these notable proteins in pathogen defense and pollen-stigma interactions.

\section{Conclusion}

For the first time, we present a large-scale investigation of gene expression in the stigmas of sheepgrass (L. chinensis), a Poaceae GSI species, using a high-throughput RNA-seq analysis. Altogether, 26,325 contigs were detected in the stigmas. Of these contigs, 1,025 showed specific or preferential expression. Quantitative real-time PCR confirmed the expression patterns of the genes examined by RNA-seq. This large-scale survey represents an efficient approach to identify the genes involved in the stigma pollination process. The functional specialization of the stigma for pollination behavior is reflected by unique features of its transcriptional profile. Many identified stigmaspecific or preferential genes were potentially involved in encoding signaling molecules, such as protein kinases and receptor-like kinases, proteins and enzymes modifying the cell wall, cuticle or ECM to facilitate the entry of the pollen tube into the stigma, and defense-related proteins that function to defend against pathogens or in response to pollination. Most of the genes identified by the RNA- seq analysis were not previously studied or reported to be expressed in stigmas, and their potential involvement in stigma development and pollen-stigma interactions opens new avenues to better understand the grass GSI system in terms of function and evolution. The future functional characterization of these genes promises to elucidate the mechanisms that underlie incompatible pollen-stigma interactions in grass GSI systems.

\section{Methods}

Plant materials, RNA extraction, library construction and illumina sequencing

The plant materials were harvested from sheepgrass plants grown under natural conditions in a field of the Beijing Botanical Garden, Chinese Academy of Sciences, Beijing, China. The stigmas were collected 1-10 hours before floret flowering by cutting the pistil below the base of the stigma, and the remainder of the pistil was used for the ovary samples. The leaves were collected from 10-day-old seedlings.

The total RNA from the mature stigmas, mature ovaries and leaves was extracted using TRIzol Reagent according to the manufacturer's instructions (Invitrogen, Carlsbad, CA, USA). The quality of the total RNA was determined using a NanoDrop 2000 (Thermo Fisher, USA). The mRNA was purified from the total RNA samples using a Dynabead mRNA Purification Kit according to the manufacturer's instructions (Invitrogen, Carlsbad, CA, USA), and the quality was assessed using an Aligent 2100 Bioanalyzer (Agilent Technologies, Inc., Waldbronn, Germany). Double-stranded cDNA was synthesized using the SuperScript Double-Stranded cDNA Synthesis Kit (Invitrogen, Carlsbad, CA, USA). Specific adapters were ligated to the fragmented cDNA and denatured to generate single-stranded cDNA followed by emulsion PCR amplification. The sequencing was performed using an Illumina HiSeq 2000 sequence analyzer at Hanyu Genomics Institute (Shanghai, China).

The sequence reads generated from each tissue sample were aligned to the reference transcriptome dataset obtained by Roche 454 pyrosequencing technology using SOAP2 software [92]. For the specific mapped unigenes with uniquely matched reads, the transcript abundance level was normalized using the RPKM (Reads Per kb per Million reads) method. The RPKM values were computed as proposed by Mortazavi et al. [93]. If there was more than one transcript for a gene, the longest one was used to calculate its transcript abundance and coverage.

\section{Real-time PCR analysis}

The total RNA $(4 \mu \mathrm{g})$ was reverse-transcribed with an oligo (dT) primer for cDNA synthesis using a SuperScript III First-Strand Synthesis Kit (Invitrogen). Gene-specific 
primers were designed using PRIMEREXPRESS software (Applied Biosystems). The primer sequences are listed in Additional file 5. Quantitative PCR assays were performed in triplicate using SYBR Green Real-time PCR Master Mix (Toyobo, Osaka, Japan) with a Bio-Rad CFX96 Real-Time Detection System. The quantitative variation in the different replicates was calculated using the delta-delta threshold cycle relative quantification method. Amplification of L. chinensis actin was used as an internal control to normalize all data.

Annotation, functional classification and pathway analysis All mapped contigs were annotated with GetORF from the EMBOSS package [94]. The ORF of each predicted protein was used for BLASTP searches against the SwissProt and NCBI nr databases with thresholds of E-value $\leq$ 1e-5. Domain-based alignments were performed against the KOG database at NCBI with a cut-off E-value of $\leq 1 \mathrm{e}-5$. $\mathrm{GO}$ annotations for describing the biological processes, molecular functions, and cellular components were analyzed by GoPipe using a BLASTP search against the SwissProt and TrEMBL databases with an E-value $\leq 1 \mathrm{e}-5$ [95]. The WEGO online tool [25] was used to classify the GO functions for all genes of sheepgrass, rice and Arabidopsis stigma-specific/preferential datasets to understand the distribution of gene functions at the macro level. Another GO analysis tool, SEA [26], was used to identify overrepresented GO terms. KEGG pathways annotations were performed using the KEGG Automatic Annotation Server (KAAS) with the bi-directional best-hit information method [27]. KAAS annotates every submitted sequence with KEGG orthology (KO) identifiers that represent an orthologous group of genes directly linked to an object in the KEGG pathways and BRITE functional hierarchy $[27,96]$. To identify transcription factor families represented in the sheepgrass stigma dataset, unigene sequences were searched against a complete list of transcription factor protein sequences of the Plant Transcription Factor Database (PlnTFDB: http://plntfdb.bio.uni-potsdam.de/v3.0/ downloads.php) using BLASTX with an E-value cutoff of $\leq 1 \mathrm{e}-10$.

\section{Availability of supporting data}

Sequence data from this article were deposited in the NCBI Sequence Read Archive (SRA065691).

\section{Additional files}

Additional file 1: Genes expressed in the stigmas, leaves, and ovaries of Leymus chinensis. RPKM: Reads Per Kilo bases per Million reads; NA: Not applicable.

Additional file 2: Comparison of gene expression between the stigmas and leaves of Leymus chinensis.
Additional file 3: Comparison of gene expression between the stigmas and ovaries of Leymus chinensis.

Additional file 4: 1,025 genes specifically or preferentially expressed in the stigma of Leymus chinensis.

Additional file 5: A list of real- time PCR primers used in the present study.

Additional file 6: The Leymus chinenesis stigma specifically or preferentially expressed genes predicted to function in signal transduction mechanisms.

Competing interests

The authors declare that they have no competing interests.

\section{Authors' contributions}

LG participated in the design and coordination of the study. ZQ, JJ, and $H X$ carried out material collection, RNA extraction and qRT-PCR. ZQ, YX, CL, CS, PX, and LX participated in data analysis. ZQ wrote this manuscript. All authors read and approved the final manuscript.

\section{Acknowledgments}

This study was funded by the the National Basic Research Program of China ("973", 2014CB138704) and National Natural Science Foundation of China (31370611).

\section{Author details}

${ }^{1}$ Key Laboratory of Plant Resources, Institute of Botany, Chinese Academy of Sciences, Nanxincun 20, Xiangshan, Beijing 100093, China. ${ }^{2}$ Beijing

Computing Center, Beijing, China.

Received: 17 December 2013 Accepted: 9 May 2014

Published: 26 May 2014

\section{References}

1. Hiscock SJ, Allen AM: Diverse cell signalling pathways regulate pollen-stigma interactions: the search for consensus. New Phytol 2008, 179:286-317.

2. Zhang YJ, Zhao ZH, Xue YB: Roles of proteolysis in plant self-incompatibility. Annu Rev Plant Biol 2009, 60:21-42.

3. de Nettancourt D: Incompatibility and incongruity in wild and cultivated plants. 2nd edition. Heidelberg: Springer; 2001.

4. Lee HS, Huang S, Kao TH: S proteins control rejection of incompatible pollen in Petunia inflata. Nature 1994, 367:560-563.

5. McClure BA: New views of S-RNase-based self-incompatibility. Curr Opin Plant Biol 2006, 9:639-646.

6. Wheeler MJ, Vatovec S, Franklin-Tong VE: The pollen S-determinant in Papaver: comparisons with known plant receptors and protein ligand partners. J Exp Bot 2010, 61:2015-2025.

7. Takayama S, Shimosato H, Shiba H, Funato M, Che FS, Watanabe M, Iwano M, Isogai A: Direct ligand-receptor complex interaction controls Brassica self-incompatibility. Nature 2001, 13:534-538.

8. Tantikanjana T, Nasrallah ME, Nasrallah JB: Complex networks of self-incompatibility signaling in the brassicaceae. Curr Opin Plant Biol 2010, 13:520-526.

9. Baumann U, Juttner J, Bian $X Y$, Langridge P: Self-incompatibility in the grasses. Ann Bot 2000, 85:203-209.

10. Klaas M, Yang BC, Bosch M, Thorogood D, Manzanares C, Armstead IP, Franklin FCH, Barth S: Progress towards elucidating the mechanisms of self-incompatibility in the grasses: further insights from studies in Lolium. Ann Bot 2011, 108:677-685.

11. Yang B, Thorogood D, Armstead I, Franklin FCH, Barth S: Identification of genes expressed during the self-incompatibility $(\mathrm{SI})$ response in perennial ryegrass (Lolium perenne L.). Plant Mol Biol 2009, 70:709-723.

12. Li XM, Nield J, Hayman D, Langridge P: Cloning a putative selfincompatibility gene from the pollen of the grass Phalaris coerulescens. Plant Cell 1994, 6:1923-1932.

13. Hackauf B, Wehling P: Approaching the self-incompatibility locus $Z$ in rye (Secale cereale L.) via comparative genetics. Theor Appl Genet 2005, 110:832-845. 
14. Yang B, Thorogood D, Armstead I, Barth S: How far are we from unravelling self-incompatibility in grasses? New Phytol 2008, 179:740-753.

15. Kakeda K: $S$ locus - linked F-box gene expressed in anthers of Hordeum bulbosum. Plant Cell Rep 2009, 28:1453-1460.

16. Quiapim AC, Brito MS, Bernardes LA, Dasilva I, Malavazi I, DePaoli HC, Molfetta-Machado JB, Giuliatti S, Goldman GH, Goldman MH: Analysis of the Nicotiana tabacum stigma/style transcriptome reveals gene expression differences between wet and dry stigma species. Plant Physiol 2009, 149:1211-1230.

17. Tung CW, Dwyer KG, Nasrallah ME, Nasrallah JB: Genome-wide identification of genes expressed in arabidopsis pistils specifically along the path of pollen tube growth. Plant Physiol 2005, 138:977-989.

18. Swanson R, Clark T, Preuss D: Expression profiling of arabidopsis stigma tissue identifies stigma-specific genes. Sex Plant Reprod 2005, 18:163-171.

19. Li M, Xu W, Yang W, Kong Z, Xue Y: Genome-wide gene expression profiling reveals conserved and novel molecular functions of the stigma in rice (Oryza sativa L.). Plant Physiol 2007, 144:1797-1812.

20. Xu XH, Chen H, Sang YL, Wang F, Ma JP, Gao XQ, Zhang XS: Identification of genes specifically or preferentially expressed in maize silk reveals similarity and diversity in transcript abundance of different dry stigmas. BMC Genom 2012, 13:294.

21. Allen AM, Lexer C, Hiscock SJ: Comparative analysis of pistil transcriptomes reveals conserved and novel genes expressed in dry, wet, and semidry stigmas. Plant Physiol 2010, 154:1347-1360.

22. Nelson CJ, Moser LE: Morphology and systematics. In An introduction to grassland agriculture. Edited by Barns RF, Miller DA, Nelson CJ. Ames, IA, USA: lowa State University Press; 1995:15-30.

23. Chen SY, Huang $X$, Yan XQ, Liang $Y$, Wang YZ, Li XF, Peng XJ, Ma XY, Zhang LQ, Cai YY, Ma T, Cheng LQ, Qi DM, Zheng HJ, Yang XH, Li XX, Liu GS: Transcriptome analysis in sheepgrass (Leymus chinensis): a dominant perennial grass of the Eurasian steppe. PLOS ONE 2013, 8:e67974.

24. Liu GS, Li XF: Germplasm of sheepgrass. Beijing, China: Science Presss; 2010.

25. Ye J, Fang $L$, Zheng $H$, Zhang $Y$, Chen J, Zhang Z: WEGO: a web tool for plotting GO annotations. Nucleic Acids Res 2006, 34:W293-W297.

26. Du Z, Zhou X, Ling Y, Zhang Z, Su Z: AgriGO: a GO analysis tool kit for the agricultural community. Nucleic Acids Res 2010, 38:W64-W70.

27. Moriya Y, Itoh M, Okuda S, Yoshizawa AC, Kanehisa M: KAAS: an automatic genome annotation and pathway reconstruction server. Nucleic Acids Res 2007, 35:W182-W185.

28. Takayama S, Isogai A: Self-incompatibility in plants. Annu Rev Plant Biol 2005, 56:467-489.

29. Wheeler MJ, de Graaf BH, Hadjiosif N, Perry RM, Poulter NS, Osman K, Vatovec S, Harper A, Franklin FC, Franklin-Tong VE: Identification of the pollen self-incompatibility determinant in Papaver rhoeas. Nature 2009, 459:992-995.

30. Ligterink W, Kroj T, Nieden U, Hirt H, Scheel D: Receptor-mediated activation of a MAP kinase in pathogen defense of plants. Science 1997, 276:2054-2057.

31. Yang KY, Liu YD, Zhang SQ: Activation of a mitogen-activated protein kinase pathway is involved in disease resistance in tobacco. Proc Natl Acad Sci U S A 2001, 98:741-746.

32. Rudd JJ, Osman K, Franklin FCH, Franklin-Tong VE: Activation of a putative MAP kinase in pollen is stimulated by the self -incompatibility (SI) response. FEBS Lett 2003, 547:223-227.

33. Li ST, Vernonica E, Franklin-Tong VE: Self-incompatibility in Papaver: A MAP kinase signals to trigger programmed cell death. Plant Signal Behav 2008, 3:243-245.

34. Luan S, Kudla J, Rodriguez-Concepcionc M, Yalovsky S, Gru-issem W: Calmodulins and calcineurin B-like proteins: calcium sensors for specific signal response coupling in plants. Plant Cell 2002, 54:389-400.

35. Yang T, Poovaiah BW: Hydrogen peroxide homeostasis: activation of plant catalase by calcium/calmodulin. Proc Natl Acad Sci U S A 2002, 99:4097-4102.

36. Albrecht V, Ritz O, Linder S, Harter K, Kudla J: The NAF domain defines a novel protein-protein interaction module conserved in $\mathrm{Ca}^{2+}$-regulated kinases. EMBO J 2001, 20:1051-1063.

37. Kim KN, Cheong Y, Pandey G, Grant J, Luan S: CIPK3, a calcium sensor-associated protein kinase that regulates abscisic acid and cold signal transduction in arabidopsis. Plant Cell 2003, 15:411-423.

38. Pandey G, Cheong YH, Kim KN, Kudla J, Luan S: The calcium sensor calcineurin B-like 9 modulates abscisic acid sensitivity and biosynthesis in arabidopsis. Plant Cell 2004, 16:1912-1924.
39. Kudla J, Xu Q, Harter K, Gruissem W, Luan S: Genes for calcineurin B-like proteins in arabidopsis are differentially regulated by stress signals. Proc Natl Acad Sci U S A 1999, 96:4718-4723.

40. Kolukisaoglu U, Weinl S, Blazevic D, Batistic O, Kudla J: Calcium sensors and their interacting protein kinases: genomics of the arabidopsis and rice CBL-CIPK signaling networks. Plant Physiol 2004, 134:43-58.

41. Batistic $O$, Kudla J: Plant calcineurin-B like proteins and their interacting protein kinases. Biochim Biophys Acta 2009, 1793:985-992.

42. Kurusu T, Hamada J, Hamada H, Hanamata S, Kuchitsu K: Roles of calcineurin B-like protein-interacting protein kinases in innate immunity in rice. Plant Signal Behav 2010, 5:1045-1047

43. Franklin-Tong VE: Signalling in pollination. Curr Opin Plant Biol 1999 2:490-495

44. Holdaway-Clarke TL, Hepler PK: Control of pollen tube growth: role of ion gradients and fluxes. New Phytol 2003, 159:539-563.

45. Franklin-Tong VE, Holdaway-Clarke TL, Straatman KR, Kunkel JG, Hepler PK: Involvement of extracellular calcium influx in the self-incompatibility response of Papaver rhoeas. Plant J 2002, 29:333-345.

46. Iwano $M$, Shiba $H$, Matoba K, Miwa T, Funato M, Pulla ET, Shimosato $H$, Takaoka A, Isogai A, Takayama S: Actin dynamics in papilla cells of Brassica rapa during self- and cross-pollination. Plant Physiol 2007, 144:72-81.

47. Wehling P, Hackauf B, Wricke G: Phosphorylation of pollen proteins in relation to self-incompatibility in rye (Secale cereale L.). Sex Plant Reprod 1994, 7:67-75

48. Prado AM, Porterfield DM, Feijo JA: Nitric oxide is involved in growth regulation and reorientation of pollen tubes. Development 2004, 131:2707-2714.

49. Cárdenas L, McKenna ST, Kunkel JG, Hepler PK: NAD(P)H oscillates in pollen tubes and is correlated with tip growth. Plant Physiol 2006, 142:1460-1468.

50. Potocký M, Jones MA, Bezvoda R, Smirnoff N, Zarsky V: Reactive oxygen species produced by NADPH oxidase are involved in pollen tube growth. New Phytol 2007, 174:742-751.

51. McInnis SM, Desikan R, Hancock JT, Hiscock SJ: Production of reactive oxygen species and reactivenitrogen species by angiosperm stigmas and pollen: potentialsignalling crosstalk. New Phytol 2006, 172:221-228.

52. Hiscock SJ, Bright J, McInnis SM, Desikan R, Hancock JT: Signalling on the stigma: potential new roles for ROS and NO in plant signalling. Plant Signal Behav 2007, 2:23-24.

53. Bolwell GP: The origin of the oxidative burst in plants. Biochem Soc Transact 1996, 24:438-442.

54. McInnis SM, Costa LM, Gutie'rrez-Marcos JF, Henderson CA, Hiscock SJ: Isolation and characterization of a polymorphic stigma-specific class III peroxidase gene from Senecio squalidus L. (Asteraceae). Plant Mol Biol 2005, 57:659-677.

55. Heslop-Harrison J: Incompatibility and the pollen-stigma interaction Ann Rev Plant Physiol 1975, 26:403-425.

56. Hiscock SJ, Hoedemaekers K, Friedman WE, Dickinson HG: The stigma surface and pollen-stigma interactions in Senecio squalidus $\mathrm{L}$. (Asteraceae) following cross (compatible) and self (incompatible) pollinations. Int J Plant Sci 2002, 163:1-16.

57. Soliday CL, Kolattukudy PE: Isolation and characterization of a cutinase from Fusarium roseum culmorumand its immunological comparison with cutinases from F. solani pisi. Arch Biochem Biophys 1976, 176:334-343.

58. Soliday CL, Flurkey WH, Okita TW, Kolattukudy PE: Cloning and structure determination of cDNA for cutinase, an enzyme involved in fungal penetration of plants. Proc Natl Acad Sci U S A 1984, 81:3939-3943.

59. Chen S, Tong X, Woodard RW, Du G, Wu J, Chen J: Identification and characterization of bacterial cutinase. J Biol Chem 2008, 283:25854-25862.

60. Hiscock SJ, Coleman J, Dewey FM, Dickinson HG: Identification and localization of an active cutinase in the pollen of Brassica napus L. Planta 1994, 193:377-384

61. Maiti IB, Kolattukudy PE, Shaykh M: Purifi cation and characterization of novel cutinase from nasturtium (Tropaeolum majus) pollen. Arch Biochem Biophys 1979, 196:412-423.

62. Knox RB, Clarke AE, Harrison S, Smith P, Marchalonis JJ: Cell recognition in plants: determinants of the stigma surface and their pollen interactions. Proc Natl Acad Sci U S A 1976, 73:2788-2792.

63. Takahashi $K$, Shimada T, Kondo M, Tamai A, Mori M, Nishimura M, Hara-Nishimura I: Ectopic expression of an esterase, which is a candidate for the unidentified plant cutinase, causes cuticular defects in Arabidopsis thaliana. Plant Cell Physiol 2010, 51:123-131. 
64. Elleman CJ, Franklin-Tong VE, Dickinson HG: Pollination in species with dry stigmas: the nature of the early stigmatic response and the pathway taken by pollen tubes. New Phytol 1992, 121:413-424.

65. Kandasamy MK, Nasrallah JB, Nasrallah ME: Pollen-pistil interactions and developmental regulation of pollen tube growth in Arabidopsis. Development 1994, 12:3405-3418.

66. Nieuwland J, Feron R, Huisman BA, Fasolino A, Hilbers CW, Derksen J, Mariani C: Lipid transfer proteins enhance cell wall extension in tobacco. Plant Cell 2005, 17:2009-2019.

67. Tian GW, Chen MH, Zaltsman A, Citovsky V: Pollen-specific pectin methylesterase involved in pollen tube growth. Dev Biol 2006, 294:83-91.

68. Kim J, Shiu SH, Thoma S, Li WH, Patterson SE: Patterns of expansion and expression divergence in the plant polygalacturonase gene family. Genom Biol 2006, 17:87.

69. Kotake T, Li YQ, Takahashi M, Sakurai N: Characterization and function of wall-bound exo- $\beta$-glucanases of Lilium longiflorum pollen tubes. Sex Plant Reprod 2000, 13:1-9.

70. Suen DF, Huang AHC: Maize pollen coat xylanase facilitates pollen tube penetration into silk during sexual reproduction. J Biol Chem 2007, 282:625-636.

71. Schopfer P: Hydroxyl radical-induced cell wall loosening in vitro and in vivo: implications for the control of elongation growth. Plant J 2001, 28:679-688.

72. McQueen-Mason S, Durachko DM, Cosgrove DJ: Two endogenous proteins that induce wall extension. Plant Cell 1992, 4:1425-1433.

73. Lee $Y$, Choi $D$, Kende $H$ : Expansins: ever-expanding numbers and functions. Curr Opin Plant Biol 2001, 4:527-532.

74. Abqamar S, Ajeb S, Sham A, Enan RM, Iratni R: A mutation in theexpansin-like A2 gene enhances resistance to necrotrophic fungi and hypersensitivity to abiotic stress in Arabidopsis thaliana. Mol Plant Pathol 2013, 14:813-827.

75. McQueen-Mason S, Cosgrove DJ: Expansin mode of action on cell walls (analysis of wall hydrolysis, stress relaxation, and binding). Plant Physiol 1995, 107:87-100.

76. Cosgrove DJ: Loosening of plant cell walls by expansins. Nature 2000, 407:321-326.

77. Riechmann JL, Ratcliffe OJ: A genomic perspective on plant transcription factors. Curr Opin Plant Biol 2000, 3:423-434.

78. Li Y, Jiang J, Du ML, Li L, Wang XL, Li XB: A cotton gene encoding MYB-like transcription factor is specifically expressed in pollen and is involved in regulation of late anther/pollen development. Plant Cell Physiol 2013 54:893-906.

79. Ito M: Conservation and diversification of three-repeat Myb transcription factors in plants. J Plant Res 2005, 118:61-697.

80. Haga N, Kato K, Murase M, Araki S, Kubo M, Demura T, Suzuki K, Müller I, Voß U, Jürgens $G$, Ito M: R1R2R3-Myb proteins positively regulate cytokinesis through activation of KNOLLE transcription in Arabidopsis thaliana. Development 2007, 134:1101-1110.

81. Kang YH, Kirik V, Hulskamp M, Nam KH, Hagely K, Lee MM, Schiefelbein J: The MYB23 gene provides a positive feedback loop for cell fate specification in the Arabidopsis root epidermis. Plant Cell 2009, 21:1080-1094

82. Punwani JA, Rabiger DS, Lloyd A, Drews GN: The MYB98 subcircuit of the synergid gene regulatory network includes genes directly and indirectly regulated by MYB98. Plant J 2008, 55:406-414.

83. D'Agostino N, Pizzichini D, Chiusano ML, Giuliano G: An EST database from saffron stigmas. BMC Plant Biol 2007, 7:53

84. Gómez-Gómeza L, Trapero-Mozos A, Gómezc MD, Rubio-Moraga A, Ahrazem O: Identification and possible role of a MYB transcription factor from saffron (Crocus sativus). J Plant Physiol 2012, 169:509-515.

85. Kuboyama T: A novel thaumatin-like protein of tobacco is specifically expressed in the transmitting tissue of stigma and style. Sex Plant Reprod 1998, 11:251-256.

86. Kumar V, Nadda G, Kumar S, Yadav SK: Transgenic tobacco overexpressing tea cDNA encoding dihydroflavonol 4-reductase and anthocyanidin reductase induces early flowering and provides biotic stress tolerance. PLOS ONE 2013, 8(6):e65535. doi:10.1371/journal.pone.0065535.

87. Devic M, Guilleminot J, Debeaujon I, Bechtold N, Bensaude E, Koornneef M, Pelletier G, Delseny M: The BANYULS gene encodes a DFR-like protein and is a marker of early seed coat development. Plant J 1999, 19:387-398.
88. Hichri I, Barrieu F, Bogs J, Kappel C, Delrot S, Lauvergeat V: Recent advances in the transcriptional regulation of the flavonoid biosynthetic pathway. J Exp Bot 2011, 62:2465-2483.

89. Eichmann R, Bisch of M, Weis C, Shaw J, Lacomme C, Schweizer P, Duchkov D, Hensel G, Kumlehn J, Hückelhoven R: BAX INHIBITOR-1 is required for full susceptibility of barley to powdery mildew. Mol Plant Microbe Interact 2010, 23:1217-1227.

90. Babaeizad V, Imani J, Kogel KH, Eichmann R, Hückelhoven R: Over-expression of the cell death regulator BAX inhibitor-1 in barley confers reduced or enhanced susceptibility to distinct fungal pathogens. Theor App/ Genet 2009, 1183:455-463.

91. Hückelhoven R, Dechert C, Kogel KH: Overexpression of barley BAX inhibitor 1 induces breakdown of mlo-mediated penetration resistance to Blumeria graminis. Proc Natl Acad Sci U S A 2003, 100:5555-5560.

92. Li R, Yu C, Li Y, Lam TW, Yiu SM, Kristiansen K, Wang J: SOAP2: an improved ultrafast tool for short read alignment. Bioinformatics 2009, 25:1966-1967.

93. Mortazavi A, Williams BA, McCue K, Schaeffer L, Wold B: Mapping and quantifying mammalian transcriptomes by RNA-Seq. Nat Methods 2008, 5:621-628.

94. Rice P, Longden I, Bleasby A: EMBOSS: the European molecular biology open software suite. Trends Genet 2000, 16:276-277.

95. Chen ZZ, Xue CH, Zhu S, Zhou FF, Ling XFB, Liu GP, Chen LB: GoPipe: streamlined gene ontology annotation for batch anonymous sequences with statistics. Prog Biochem Biophys 2005, 32:187-191.

96. Mao X, Cai T, Olyarchuk JG, Wei L: Automated genome annotation and pathway identification using the KEGG Orthology (KO) as a controlled vocabulary. Bioinformatics 2005, 21:3787-3793.

doi:10.1186/1471-2164-15-399

Cite this article as: Zhou et al:: The large-scale investigation of gene expression in Leymus chinensis stigmas provides a valuable resource for understanding the mechanisms of poaceae self-incompatibility. BMC Genomics 2014 15:399.

\section{Submit your next manuscript to BioMed Central and take full advantage of:}

- Convenient online submission

- Thorough peer review

- No space constraints or color figure charges

- Immediate publication on acceptance

- Inclusion in PubMed, CAS, Scopus and Google Scholar

- Research which is freely available for redistribution 